\title{
Computer Technology in Psychological Experiment Teaching
}

\author{
Zhang Mei \\ Department of Psychology, Jianghan University, Wuhan, China
}

\begin{abstract}
Compared with mechanical and electronic instrument, computer technology in psychological experiment teaching has obvious advantages. A variety of experimental software has been used for different types of psychological experiment teaching. Computer technology has improved the efficiency and quality of psychological experiment teaching obviously. At the same time, it has some shortcomings. The feasible way is to establish a teaching model of computer-based experiment complemented with instrument.
\end{abstract}

Index Terms: computer software; multimedia; computer network; experiment; psychology; teaching

(C) 2012 Published by MECS Publisher. Selection and/or peer review under responsibility of the International Conference on E-Business System and Education Technology

\section{Introduction}

Psychology is built on the basis of experiment. Most knowledge of modern psychology comes from experimental psychology research. Experiment is an important part of many courses of psychology, such as general psychology, experimental psychology, cognitive psychology, psychological statistics, psychometrics, psychophysiology, developmental psychology, educational psychology, psychological counseling, psychotherapy et al.

Because of the nature of psychology, it must be taught and learnt through experiment. Teachers need to demonstrate a variety of psychological phenomena and many classic psychological experiments. Students need to operate psychological instrument, collection and process experimental data and write experiment reports. It is the necessary condition of psychological experiment teaching to have wide available and well-functioning experimental instrument and equipment.

\section{Shortcomings of mechanical and electronic instrument}

Before the 90s of the 20th century, most of the domestic department of psychology used mechanical and electronic instrument in experiment teaching. That has obvious shortcomings.

\footnotetext{
* Corresponding author.

E-mail address: zm303@yahoo.cn
} 
- The number of experiments is limited. Some of them are demonstrated experiments of general psychology and experimental psychology. Others are experiments of sensation, perception, attention, learning and memory. Higher, more complex experiments can not be performed.

- Most of the domestic mechanical and electronic instrument of psychological experiment are rough designed, and lack of rigorous measurement standards and specification of products. They have poor accuracy and reliability. So they can not meet the requirements of psychological experiment teaching.

- The investment is large but the efficiency is low. One instrument only can do one kind of experiment. The same instrument needs to be purchased several ones for several students groups. Most of the instruments are used only one or two times a year.

- The cost of maintenance is very high. It need a lot of time to test and prepare the instruments. The accessories are easily to damage. The performance is easily out of date. After a few years the instruments need to be updated.

\section{Advantages of computer in psychological experiment teaching}

Since the 90s of the 20th century, many computer-aided tools for psychological experiment teaching began to appear in China. "It has been a trend to computerize psychological experiment teaching. Computer with psychological experiment software, special interface and external device has been used in psychological experiment teaching [1]." Peking University and Beijing Psyche-Ark science \& technology development Co., Ltd. developed a series of psychology application software (Psykey). Beijing Normal University developed an experimental system for psychology (ExpPsy).

Compared with mechanical and electronic instrument, computer system for psychological experiment teaching has obvious advantages.

- Computer can precisely present and control experimental conditions. According to the requirement of experimenter, computer can present visual stimulation, auditory stimulation and movement stimulation. It can present problem to the subject by simulating real or imagined situation.

- Computer can measure and record the subject's response accurately and automatically. It greatly reduces the workload of experimenters.

- Using computer can reduce the influence of the experimenter to the subject.

- Computer can provide feedback immediately. It can give feedback by data, graph, words, sound and images witch based on the reaction of the subject.

- Computer makes it easily and quickly to process the experimental data. Using statistical software, computers can collect statistics rapidly. It improves the efficiency of experiments.

- Computer makes it possible for users to design the experiments. Experimenters can design experimental materials, conditions and modes of response by themselves. Computer helps to expand the subjects of experiment and promote innovative experiments.

At present, computer system for psychological experiment is widely used in psychology teaching at university. Computers have replaced some of the traditional instruments of psychological experiment. Over a hundred of psychological experiments can be performed by computers. They relate to general psychology, experimental psychology, cognitive psychology, psychometrics, developmental psychology, educational psychology, physiological psychology, psychological counseling and psychotherapy et al.

For example, the Psykey Psychology Application System includes five series of psychological experiment software. Please see table 1.

Many higher, more complex psychological experiments were impossible to be performed before, they can be performed now. The efficiency and quality of psychological experiment teaching has been improved remarkably. 
Table 1. Psykey Psychology Application System

\begin{tabular}{|c|c|c|c|}
\hline \multirow{2}{*}{ Series } & \multicolumn{3}{|c|}{ Product Of Psykey } \\
\hline & Name & Edition & Number of software \\
\hline 1 & $\begin{array}{l}\text { PsyKey Psychology } \\
\text { Teaching System }\end{array}$ & V3.0 & 110 experiments \\
\hline 2 & $\begin{array}{c}\text { PsyKey Psychological } \\
\text { Test System }\end{array}$ & V2.0 & 87 scales \\
\hline 3 & $\begin{array}{l}\text { PsyKey Personnel } \\
\text { Evaluation System }\end{array}$ & V1.0 & 21 tests \\
\hline 4 & $\begin{array}{c}\text { PsyKey Exercise } \\
\text { Psychology Test System }\end{array}$ & V1.0 & 20 scales and 11 tests \\
\hline 5 & $\begin{array}{c}\text { PsyKey Mental File } \\
\text { System }\end{array}$ & BS & 79 scales \\
\hline
\end{tabular}

\section{Computer, multimedia and computer network technology in different types of psychological experiment teaching}

\subsection{Demonstration experiment of psychology}

Computers and multimedia provide a mode of human-machine interaction and the environment of multisensory stimulation. They can demonstrate various phenomena of general psychology, experimental psychology, educational psychology and developmental psychology. They can also demonstrate the process of experiments. The experimental instruction, stimulus, response, procedure and results can demonstrate visually on the large screen. By human-machine interactions, words, illustrations, sounds and images computers provide large amount of information to the psychological experiment teaching and raise the liveliness and interest of teaching. It makes students to understand knowledge quickly and accurately.

\subsection{Experiment of basic psychology}

Experimental psychology and cognitive psychology are the professional required courses of psychology. Compared with other courses, their contents of experiment are the most and their hours of experiment are the longest. The hours of experimental teaching in the proportion of the total hours are accounted for about onethird. About $60 \%$ to $90 \%$ of the experiments can be done by the computer system of psychological experiment.

Currently, which the domestic universities use generally is PsyKey Psychology Teaching System and ExpPsy Experimental System for Psychology.

Take the PsyKey Psychology teaching system as an example. The software section contains 110 experiments, covering a number of the branch of psychology. It has lively multimedia presentation capabilities, powerful data processing capabilities, the custom functions of experimental parameters and list. The external hardware is designed based on the precision requirements of psychological experiments. The module which is specifically designed for the large-scale network experimental teaching (Net module) is very convenient for users to collect experimental data and set the overall experimental parameters. 
Table 2. Psykey psychology teaching system

\begin{tabular}{|c|c|c|}
\hline \multirow{2}{*}{ Series } & \multicolumn{2}{|c|}{ Content } \\
\hline & Name of category & $\begin{array}{l}\text { Number of } \\
\text { experiment }\end{array}$ \\
\hline 1 & $\begin{array}{c}\text { Demonstration } \\
\text { experiments of } \\
\text { general psychology }\end{array}$ & 13 \\
\hline 2 & $\begin{array}{l}\text { Experiments of } \\
\text { child psychology }\end{array}$ & 15 \\
\hline 3 & $\begin{array}{c}\text { Experimental } \\
\text { determination of } \\
\text { primary mental } \\
\text { abilities }\end{array}$ & 28 \\
\hline 4 & $\begin{array}{c}\text { Classic experiments } \\
\text { of psychology }\end{array}$ & 31 \\
\hline 5 & $\begin{array}{l}\text { Experiments of } \\
\text { cognitive } \\
\text { psychology }\end{array}$ & 17 \\
\hline 6 & $\begin{array}{l}\text { Experiments of } \\
\text { man-machine } \\
\text { interaction and } \\
\text { engineering } \\
\text { psychology }\end{array}$ & 6 \\
\hline
\end{tabular}

Take the ExpPsy Experimental System for Psychology as an example. It consists of 31 experiments of experimental psychology and cognitive psychology. Teachers can choose the experimental materials and define the experimental parameters by them selves. The experiment process control is standard. The results of experiments are accurate and reliable. It is more quickly to design and prepare experiments and to collect and analyze experimental data. Experimenters could query for experimental data of individual and statistical data at any time. The system has a complete help system. Use of this system can achieve network experiment teaching. It has the capabilities of network data management and improves the efficiency of data collecting and processing. 
Table 3. Exppsy experimental system for psychology

\begin{tabular}{|c|c|c|}
\hline \multirow{2}{*}{ Series } & \multicolumn{2}{|c|}{ Content } \\
\hline & Name of category & $\begin{array}{l}\text { Number of } \\
\text { experiment }\end{array}$ \\
\hline 1 & $\begin{array}{l}\text { Experiment of } \\
\text { traditional } \\
\text { psychophysics }\end{array}$ & 5 \\
\hline 2 & $\begin{array}{l}\text { Experiment of } \\
\text { reaction time }\end{array}$ & 3 \\
\hline 3 & $\begin{array}{l}\text { Experiment of } \\
\text { signal detection } \\
\text { theory }\end{array}$ & 3 \\
\hline 4 & $\begin{array}{l}\text { Experiment of } \\
\text { information } \\
\text { processing }\end{array}$ & 7 \\
\hline 5 & $\begin{array}{l}\text { Experiment of } \\
\text { learning and } \\
\text { memory }\end{array}$ & 8 \\
\hline 6 & $\begin{array}{l}\text { Experiment of } \\
\text { research }\end{array}$ & 5 \\
\hline 7 & Tool software & 2 \\
\hline
\end{tabular}

"The system is an open design platform of psychological experiment. Experimenters can design experimental material according to their needs. They can define the parameter of experiment number, experimental control, experimental treatment, interstimulus interval and delayed time, etc. The system can improve the flexibility and creativity of experimenters while they design teaching and materials of experiment [2]. "

\subsection{Experiment of psychological statistics}

In order to get valuable conclusion, the data of psychological experiment must be appropriate process and analysis. Psychological statistics tells the student how to process and analysis psychological experiment data. With powerful computing features, computer has been applied widely and deeply in psychological statistics. The most commonly used software for psychological statistics is SPSS (Statistical Package for the Social Science) and SAS (Statistics Analysis System). The very important part of psychological statistics teaching is to teach students to use statistical software. Currently, laboratory LAN installed statistical software is the major approach of psychological statistics experiment teaching.

\subsection{Experiment of psychometrics}

In addition to the test which needs manual tools, most of the psychological test can be compiled into computer software. The test programs are presented on the screen. Subjects make response by entering symbol, 
pressing response key or operating the mouse. Computers record and storage their response, and calculate test score by corresponding program. The test score is displayed by data or chart, given some analysis and explanation. Students can complete a variety of psychological tests individually in a relatively short period of time, and can also copy and print the results.

At present, computer software of psychological tests is very rich. The more representative one is Psykey Psychological Test System. It contains 87 commonly used scales. The interpretations of the results are detailed and professional. It has very powerful capabilities of data processing, illustrated statistical report and very friendly user interface. The self-set function is complete. The system can support a variety of test methods such as written test, network test and cursor reading test. Users can also set up norms, scale lists, user permissions, user adscription, report formats and other projects. The data is very easy to dock with other software and be converted into other types.

\subsection{Experiment of psychophysiology}

Electrophysiological measurement technique and computer technology can be used to measure the parameter of psychophysiology. With special software, the parameter of respiration, heart rate, skin resistance and brain wave can be measured, recorded and displayed real-timely by connected sensor and computer. This technology greatly enhanced the efficiency and accuracy of psychophysiology experiment. It has a vivid, visual effect. It makes the processing of experimental data more convenient. Computer-controlled multi-channel physiological recorder can also be used in biofeedback and psychotherapy.

Table 4. Psykey psychological test system

\begin{tabular}{|c|c|c|}
\hline \multirow{2}{*}{ Series } & \multicolumn{2}{|c|}{ Content } \\
\hline & Name of category & $\begin{array}{c}\text { Number of } \\
\text { scale }\end{array}$ \\
\hline 1 & Mental health & 18 \\
\hline 2 & Personality & 14 \\
\hline 3 & $\begin{array}{l}\text { Abilities and } \\
\text { interests }\end{array}$ & 6 \\
\hline 4 & Clinical diagnosis & 11 \\
\hline 5 & Learning & 11 \\
\hline 6 & $\begin{array}{c}\text { Social } \\
\text { communication }\end{array}$ & 9 \\
\hline 7 & Self & 3 \\
\hline 8 & Life stress & 11 \\
\hline 9 & Other & 4 \\
\hline
\end{tabular}




\subsection{Experiment of behavior observation}

The integrated use of computer and multimedia provides a powerful tool for the study of human behavior and social interaction in a particular situation. The courses of social psychology, developmental psychology, management psychology, psychological counseling and psychotherapy have experiments of behavior observation. Subjects need to be observed without interference completely. The ideal way is to experiment in a specially designed behavior observation room.

The behavior observation room is divided into two spaces by one-way glass. One side is the activity room where the subject is in. There are computer, projector, speaker, television set, hidden video camera and acoustical pickup that have been installed in it. The other side is the observation room where the experimenter is in. All of the devices in the activity room have been connected with the computers in the observation room. The experimenter controls the presentation of stimulate in the activity room through multimedia control system, and gets video and audio records of the subject. The material is true and natural, and can be observe and study repeatedly.

\subsection{Information system of psychological experiment teaching}

To build a highly integrated information management platform for psychological experiment teaching is not only necessary but possible. To combine the various instruments, device, experimental technique, instructional materials, learning material and information of teachers and students into computer, multimedia, simulation technology and network may create a multi-functional psychological experiment teaching information system. This system can be used to assist teaching, manage the laboratory and actualize virtual experiment. "It improves the informationization, efficiency and openness of psychological experiment teaching. The laboratory resource can be used and coordinated comprehensively. The teachers and the students can be provided intelligent services [3]. "

"The computerized psychological experiment is not only to improve the experimental condition, enhance the level of experimental control, but also liberate the experiment from the laboratory. It makes it possible to implement network and distance learning [1]." Computer-centered psychological experiment teaching information system is the direction of the development of psychological experiment teaching.

\section{Review of computerized psychological experiment teaching}

The application of computer technology in psychological experiment teaching has achieved remarkable result. However there are aspects of shortcomings. For example, the stimulus is usually presented on a computer screen or projection screen. The single way of presentation of stimulus fatigues the subject easily. "To do psychological experiment in the computer room is very different from the real situation. The external validity of psychological experiment is reduced [1]." What the students usually do during experiments is simply to press the response button. They have no chance to get exercise on operating equipments, controlling experimental conditions, observing the subjects, measuring and recording the subject 's response. Computers prevent the students from grasping the principles and methods of psychological experiment and learning how to use psychological experiment apparatus and equipment. "During computerized psychological experiment, some inherent psychological change and unexpected response of subjects can not be observed and recorded by computer. The students lose the possibility to explore the issue deeply [4]." These questions await further study. 


\section{Conclusion}

The application of computer system for psychological experiment teaching has developed rapidly in the last decade. Compared with the previous manual and electrical instrument, its advantages are obvious. It can precisely control the experimental conditions, accurately record reaction time, quickly process the experimental data, provide immediate feedback and permit the experimenter to design experiment according to their own needs. Currently, computer system for psychological experiment has been an indispensable means of teaching at universities which replaces some of the traditional psychological experiment instrument. It makes it possible to perform many higher, more complex psychological experiments which could not be performed before. The efficiency and quality of psychological experiment teaching has been greatly improved.

At the same time, computer system for psychological experiment teaching has some shortcomings. Some traditional apparatus and equipment of psychological experiment need to be kept. For some of the psychological experiment can not rely on computer entirely. Using traditional apparatus and equipment will help the students to train their initiative, observation ability and operation skills. Currently the feasible way of psychological experiment teaching is to establish a model of computer-based experiment complemented with instrument.

\section{References}

[1] Zhang Yi-Zhong, "Psychological Experiment Teaching and Development", Laboratory Research and Exploration, Beijig, vol. 21 no. 2, pp. 17-18, Apr. 2002. (in Chinese)

[2] Zhang Xue-min, Shu Hua, Zhang Ya-Xu, "Thinking and Practice of Teaching Reform in Theory and Practice of Experimental Psychology”, Higher Education, Lanzhou, no. 6, pp. 33-38, 2001. (in Chinese)

[3] Xiao Xin, "Constructing and Planning of Laboratory Information Platform", The Second Seminar of Psychology Laboratory Constructing of National University, Guangzhou, 2006. (in Chinese)

[4] Xu Xue, "Psychological Experiment Teaching Reform in Higher Normal University" , Journal of Yanbei Normal University, vol. 20, no. 3 , pp. 66-68, Jun. 2004. (in Chinese) 